\title{
Bailout technique to remove a distal protection device ('Filtrap') when the retrieval and delivery catheters could not pass through the deployed stent
}

\author{
Tsuyoshi Honda, Ikuo Misumi \\ National Hospital Organization Kumamoto Saisyunsou Hospital, Koushi city, Japan
}

Adv Interv Cardiol 2017; 13, 2 (48): 157-159

DOI: https://doi.org/10.5114/pwki.2017.67992

\section{Introduction}

Although aspiration thrombectomy might be considered only in patients with ST-segment elevation myocardial infarction (STEMI) according to the European Society of Cardiology guidelines, small studies showed that aspiration thrombectomy and/or distal embolic protection might be effective to prevent slow flow/no flow during percutaneous coronary intervention $(\mathrm{PCI})$ in non ST-segment elevation myocardial infarction (NSTEMI) patients with thrombus or attenuated plaque according to Japanese Circulation Society (JCS) Guidelines for management of acute coronary syndrome without persistent ST-segment elevation [1-6]. Distal embolic protection should be considered in NSTEMI patients with thrombus or attenuated plaque in Japan, which is supported by these Guidelines. However, data to support distal protection in STEMI/NSTEMI are scarce, and this technique is not broadly adopted elsewhere [1, 2]. Either occlusive or filter-based systems can catch thrombus and/or debris that may damage distal tissue. Their insert packages recommend aspiration in the culprit lesion before removal to prevent distal embolism on removal. A filter-based device (Filtrap, Nipro, Japan) was designed to capture debris while preserving coronary blood flow and making the procedure simple and smooth $[5,6]$.

In this article, we present a bailout technique to remove the Filtrap device when the retrieval and delivery catheters could not pass through the deployed stent.

\section{Case report}

A 72-year-old Japanese man visited the outpatient clinic of our institution because of frequent chest pain. He was diagnosed with NSTEMI because his electrocardiogram demonstrated that the ST segments in V5-6 were depressed and the laboratory test on admission showed that troponin I was increased. Coronary angiography (CAG) revealed severely stenotic lesions in the left anterior descending coronary artery (LAD) (Figure $1 \mathrm{~A}$ ). He underwent $\mathrm{PCI}$ for the LAD lesion. A 6.5-Fr TYPE-M SheathLess guiding catheter (Asahi intecc, Japan) was positioned in the left main tract by the procedure described previously $[7,8]$. After wiring into the LAD with a Sion blue guidewire (Asahi intecc, Japan), we evaluated the culprit lesion by Navifocus WR intravascular ultrasound (IVUS) (Terumo, Japan). A distal protection device (Filtrap) was deployed at the distal site of the culprit lesion because IVUS showed attenuated plaque (Figure $1 \mathrm{~B}$ ). After pre-dilatation was performed using a $3.0 \times 13 \mathrm{~mm}$ Lacrosse NSE balloon catheter (Goodman, Japan), a $3.0 \times$ $33 \mathrm{~mm}$ Ultimaster stent (Terumo, Japan) was deployed at the proximal LAD (Figure $1 \mathrm{C}$ ). After evaluation by IVUS (Figure $2 \mathrm{~A}$ ), post-dilatation was performed using a $3.0 \times$ $13 \mathrm{~mm}$ Lacrosse NSE balloon catheter (Goodman, Japan). After aspiration using Thrombuster III SL (Kaneka, Japan), the retrieval catheter was inserted to remove the Filtrap (Nipro, Japan). However, it could not advance at the proximal site of the deployed stent. Next, the delivery catheter was inserted, but it could not advance at the proximal site of the deployed stent. Post-dilation was then performed using a $3.0 \times 13 \mathrm{~mm}$ Lacrosse NSE balloon catheter (Goodman, Japan). Although a Cokatte (Asahi intecc, Japan) hydrophilic-coated small guiding catheter was inserted with the distal anchor technique using a $3.0 \times$ $15 \mathrm{~mm}$ TREK balloon catheter (Abbott, USA), it stopped at the proximal edge of the deployed stent. Finally, the delivery catheter was inserted into a Cokatte catheter, and it could then pass through the stent (Figure 2 B). The Filtrap was removed, and the final CAG result was excellent (Figure $2 \mathrm{C}$ ).

\section{Corresponding author:}

Tsuyoshi Honda PhD, National Hospital Organization Kumamoto Saisyunsou Hospital, 2659 Suya, 861-1196 Koushi city, Japan, phone: 8196242 1000, e-mail: tsuyohonda-circ@umin.ac.jp

Received: 3.10.2016, accepted: 11.01.2017. 

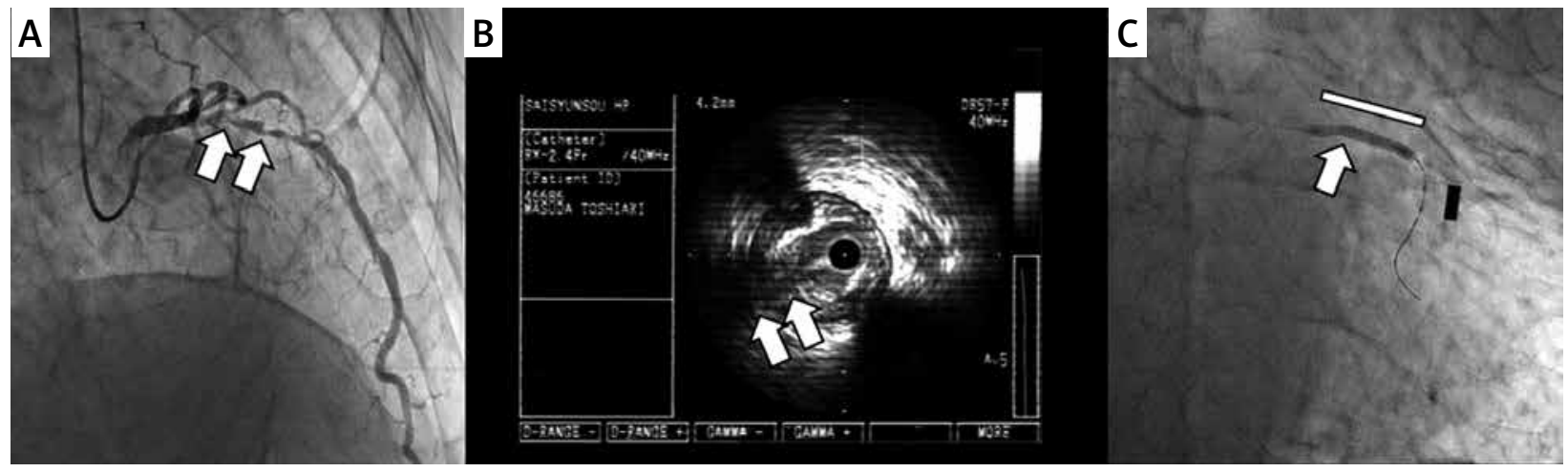

Figure 1. Results of $\mathrm{PCl}$ in this case. $\mathbf{A}$ - severe stenoses in the LAD (white arrows). $\mathbf{B}$ - attenuated plaque (white arrows) on IVUS before PCI. C - stenting (white line) during distal protection with Filtrap (black line), mild curved stent (white arrow)
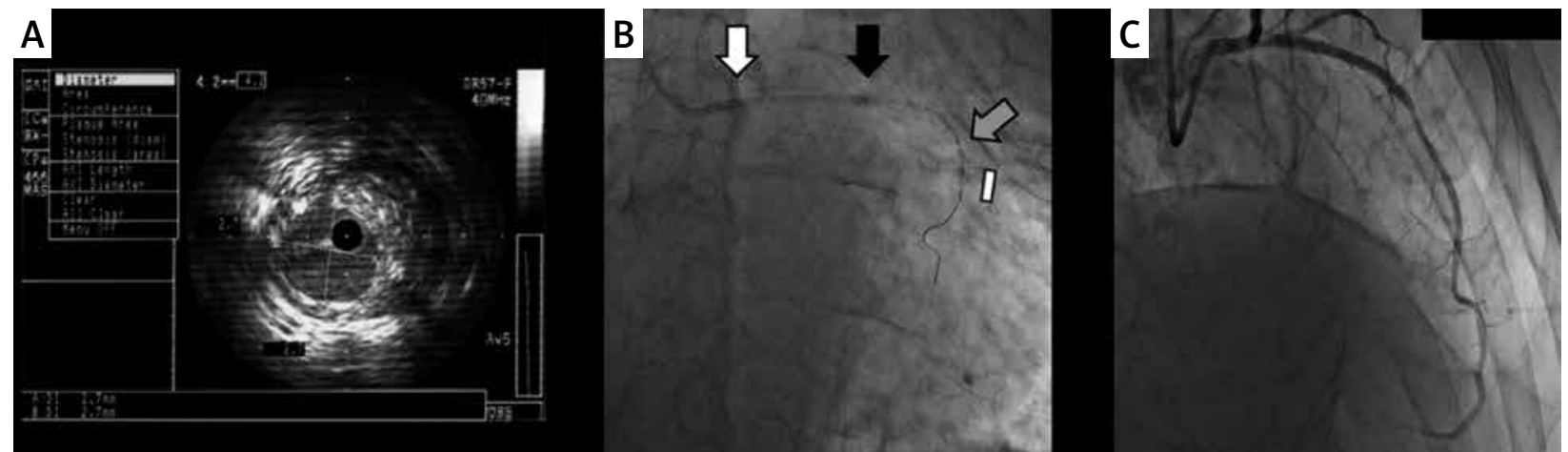

Figure 2. Results of PCI in this case. A - IVUS after stenting (\#6). B - removal of Filtrap (white line) using a delivery catheter (gray arrow) through Cokatte (black arrow) inserted into the guiding catheter (white arrow). C - final shot

\section{Discussion}

We report a case of bailout technique to remove a Filtrap device when the retrieval catheter and delivery catheter could not pass through the deployed stent.

It is well known that distal embolic protection might be an effective strategy to prevent slow flow/no reflow during $\mathrm{PCl}$ [3-6]. The merits of distal protection using the Filtrap are the preservation of coronary blood flow and the simplicity of the procedure. In this case, it was impossible to remove the Filtrap using the retrieval and delivery catheters, because they did not advance at the proximal site of the deployed stent. Although we speculated that it might be associated with insufficient expansion and protruded struts of the deployed stent, IVUS showed that the stent was roundly expanded and the diameter was about $2.7 \mathrm{~mm}$. We added post-dilatation with a $3.0 \mathrm{~mm}$ semi-compliant balloon (16 atm, $3.25 \mathrm{~mm}$ ) to gain enough expansion of the stent, but the retrieval catheter could not pass through the stent. The IVUS findings showed that the removal failure might not be associated with insufficient expansion or deformation of the deployed stent.
The package insert recommends that the Filtrap should be removed using a straight catheter with an inner diameter $>1.40 \mathrm{~mm}$, if removal using the retrieval and delivery catheters is not possible (Figure 2). However, insertion of this catheter might damage the coronary vascular intima. Recent development of $\mathrm{PCl}$ devices allows deep seating of child catheters using the "mother and child" technique [7-9]. In this case, we used Cokatte to remove the Filtrap, but this attempt failed. The retrieval, delivery and straight catheters could not advance at the stent bent by calcified plaque, because it is well known that a new drug-eluting stent (Ultimaster) has very high conformability to the vessel wall (Figure $1 \mathrm{C}$, white arrow) [10].

In conclusion, we present a bailout technique to remove the Filtrap using the "mother and child" technique, when it is difficult to remove it using a retrieval, delivery or straight catheter.

\section{Conflict of interest}

The authors declare no conflict of interest. 


\section{References}

1. Windecker S, Kolh P, Alfonso F, et al. 2014 ESC/EACTS Guidelines on myocardial revascularization: The Task Force on Myocardial Revascularization of the European Society of Cardiology (ESC) and the European Association for Cardio-thoracic Surgery (EACTS) Developed with the special contribution of the European Association of Percutaneous Cardiovascular Interventions (EAPCI). Eur Heart J 2014; 35: 2541-619.

2. JCS Joint Working Group. Guidelines for management of acute coronary syndrome without persistent ST segment elevation (JCS2012). Available at: http://www.j-circ.or.jp/guideline/pdf/ JCS2012_kimura_h.pdf.

3. Vlaar PJ, Diercks GF, Svilaas T, et al. The feasibility and safety of routine thrombus aspiration in patients with non-ST-elevation myocardial infarction. Catheter Cardiovasc Interv 2008; 72 : 937-42.

4. Limbrumo U, Ebert AG, Galli M. Filters to prevent distal embolization during coronary artery stenting: the risk of mousetrap. J Invasive Cardiol 2006; 18: E131-3.

5. Iwasaki K, Matsumoto T, Aono H, et al. Prevention of coronary slow flow/no reflow during percutaneous coronary intervention by the use of embolic protection device, 'Filtrap'. Cardiovasc Interv Ther 2010; 25: 46-9.

6. Isshiki T, Kozuma K, Kyono H, et al. Initial clinical experience with distal embolic protection using "Filtrap", a novel filter device with a self-expandable spiral basket in a patients undergoing percutaneous coronary intervention. Cardiovasc Interv Ther 2011; 26: 12-7.

7. Honda T, Fujimoto K, Miyao Y. Feasibility of virtual 3-Fr percutaneous coronary intervention using standard guiding catheters. Postep Kardiol Inter 2014; 10: 231-7.

8. Honda T, Fujimoto K, Miyao Y. Successful percutaneous coronary intervention using a 4-in-3 "slender mother and child" PCI technique. Postep Kardiol Inter 2013; 9: 286-90.

9. Takahashi A, Taniguchi N, Yamada T, et al. The novel 4.5F Cokatte catheter for stent delivery facilitation in complex coronary artery lesions. Cardiovasc Revasc Med 2014; 15: 346-9.

10. Lesiak M, Araszkiewicz A, Grajek S, et al. Long coronary lesions treated with thin strut bioresorbable polymer drug eluting stent: experience from multicenter randomizes CENTURY II study. J Interv Cardiol 2016; 29: 47-56. 